\title{
Music Education as a Mirror to Humane Education
}

\author{
David T. Hansen \\ Teachers College, Columbia University
}

The following text derives from serving on a panel organized to respond to Randall Allsup's Remixing the Classroom: Toward an Open Philosophy of Music Education, held at Teachers College, Columbia University, October 11, 2016.

Keywords: philosophy, music, education, dignity, moral, ethical

$\mathrm{I}$

$\mathrm{t}$ is an honor to have the opportunity to respond to Randall Allsup's recent book. I have known and interacted with Randall for many years. We have developed a long-standing conversation about education writ large, and about our respective fields of music education and philosophy of education. I have learned from and with Randall why music and philosophy have so much to say to one another, and why this has been the case for thousands of years. For example, the writings of Confucius and Lao Tzu encompass a distinctive focus on notions of harmony. They characterize the latter as an ethical-aesthetic relation between person and person, and between person and world, which embodies numerous motifs from musical practice and insight. During the same historical era, on the other side of the globe, Plato argued that music, alongside poetry and gymnastics, constitutes the very core of education. Music forms the soul of the individual person, generating a balanced, self-controlled orientation toward all the affairs of life. Moreover, music's formative effects are lifelong. Plato goes so far as to suggest that in the absence of a substantive musical education, both individuals and their society will literally unravel. They will lose a sense of centeredness, of balance, of harmony, and fall into discord and violence, with themselves as well as with others.

(C) David T. Hansen. 2017. The content of this article is the sole responsibility of the author. The ACT Journal and the Mayday Group are not liable for any legal actions that may arise involving the article's content, including, but not limited to, copyright infringement. 
Philosophers have learned from musicians and music scholars why music is constitutive of virtually every human culture that has emerged on the planet. Philosophers have learned to recognize music's capacious nature, its literally boundless 'being-in-the-world', to use a poetic trope to capture a very concrete reality. Musical sound, rhythm, movement, and more, are as expressive of ideas as are prose and every other medium that comes to mind. When I listen to some of my own favorite musical pieces, ranging from Mahler's Symphony \#9 to B.B. King's "Born Again Human," I am in the presence of ideas as well as of feeling, imagination, and a whole constellation of aesthetic and moral sentiments. These responses attest to the ideas expressed in and through the music. In Mahler: ideas about the fundamentally erotic nature of the human being, not in the contemporary sexual sense of that term but in the ancient Greek sense of the human being as a creature marked by a profound, almost inexpressible yearning for meaning, for beauty, for justice-even if this yearning is all too often smothered, silenced, dissipated, or cheapened by nihilistic, morally ugly, and unjust aspects of society. In B. B. King: the deep truth that no human being can make it on her or his own. I am because you are. His music shows this truth-or, better, enacts itrather than 'commenting' on it.

Music and philosophy go far, far back together in human culture, and a singular feature of Randall's new book is how marvelously he demonstrates their organic union. I would call his book philosophically joyful, which I recognize is not a typical qualifier deployed for a scholarly text produced by a member of the academy. But it is a moving book, a book whose prose moves and is remarkably animated, motored by an underlying commitment to enriching and humanizing music education. I would characterize the joy that constitutes the argument as sobered and knowing. Again, 'a knowing joy' is an unusual remark to characterize a scholar's orientation. But I am thinking here of what the 17th Century essayist Michel de Montaigne had in mind when he wrote: "The most express [visible] sign of wisdom is unruffled joy." Randall's book is a truly composed reflection: it conveys a mood of both composure and of urgency, of wonder and of concern. Every note in the book seems essential to its overall structure and theme. Put another way, every sentence in the book feels like the precipitate of a long process of thought, of rumination, of contemplation. Here I'm reminded of something the 19th Century essayist Ralph Waldo Emerson once said about the aforementioned

Hansen, David T. 2017. Music education as a mirror to humane education. Action, Criticism, and Theory for Music Education 16 (1): 95-100. doi:10.22176/act16.1.95 
Montaigne, who was a renowned wordsmith in his own day and remains so in our time. Emerson said that Montaigne's sentences are so full of life that if you cut one of them it would bleed.

Randall's vivid book is written out of a deep well of concern for the current form and future trajectory of music education. He works out a fresh perspective: a reconstructed platform for both thought and action that takes seriously what he regards as the very best from traditions of music education, while also taking equally seriously the human beings who in flesh and blood participate in music education. The book is not revolutionary in a political sense of calling for a complete break with the past and a radical recommencement. As Randall makes plain, such a break is in fact impossible, for the very concept of a 'break' itself comes from our past and the ever-dynamic languages and ways of thinking it has bequeathed to us. It is what we've been bequeathed from the past that allows us to criticize the past, as well as the present. We can never do so de novo.

However, Randall's argument strikes me as quite revolutionary in calling for a turn-literally, a turn (a revolving) in the music education community's perception of what music education might come to mean, and what it might look like in concrete practice, from a fuller, more inclusive perspective. Here I discern again how music and philosophy can cross paths so organically. In reading the book, I could not help but think of Plato's still beautiful, dramatic conception of education as 'a turning of the soul' so that people can truly learn to look at the world, and to regard one another and themselves, in the light of justice.

What is the 'fuller, more inclusive' perspective to which I've referred? Randall's whole book constitutes a response to this question. In my view, the response has to do with the idea of dignity. This term has an old-fashioned resonance to it, but it is a word I have been absorbed with these days in contemplating our society's regard-or, more to the point, its lack of regard-for the men and women who have taken up the infinitely important, and infinitely difficult, endeavor that we call teaching. I do not have in mind the (tiresome) Rodney Dangerfield complaint that 'we teachers don't get no respect'. I am thinking more of contemporary society's ever-increasing treatment of everything and everybody as mere instrumentalities -including education itself, which is more and more perceived as merely a means to future economic ends. This societal ethos is having a demoralizing effect on educators across the entire system, from kindergarten through graduate school.

Hansen, David T. 2017. Music education as a mirror to humane education. Action, Criticism, and Theory for Music Education 16 (1): 95-100. doi:10.22176/act16.1.95 
Randall's endeavor calls to mind a quite compelling conception of dignity that can be traced back to Immanuel Kant: namely, that dignity means to regard and treat other persons as ends in themselves, never as a mere means to our or others' ends. This picture of dignity has a 'commandingness' built into it that is hard to meet in everyday practice, given human fallibility, frailty, and vulnerability. However, this picture can also serve as a regulative ideal: literally, as an ideal that can 'regulate', i.e. guide, the thought and the practice of the music educator. It is not a regulation imposed from the outside or through an external authority. On the contrary, it constitutes a beautiful mode of self-regulation. To acknowledge the dignity of the student is instantaneously to appreciate that he or she brings to the music education setting a whole history of human experience, including with music. Moreover, the student-whatever her or his age-brings perhaps unarticulated ideas, intuitions, and intimations about music that nobody has ever drawn out from the student, or ever provided a platform to bring them into form.

Music education also involves, of course, music! What might it mean to refer to the dignity of music itself? Is the question a misalignment of concepts? Isn't dignity fundamentally a moral and ethical term, pertaining to persons? A lesson I take from Randall's book is that there is very much a moral and ethical relation between the student, the teacher, and music itself. Music 'summons' us. Like other modes of art, it calls out to us, pulls us near, draws us in. To personify music for a moment: it asks us for a response. Music does not want to be treated as a mere means to our or others' ends. Music asks us to meet it halfway. As an art, it was here before we were. It has always already made its presence felt, and made it possible for people to engage in the very acts of music-making, music-listening, music-thinking, and all the rest. And, importantly, music has always already been here before educators take on the task of teaching it. Randall is emphatic in reminding us of how dynamic music has always been, and how every tradition we can think of keeps evolving, especially when it comes into contact with other traditions. Music has its structures, forms, and modes, which 'ask' the teacher and the student to respect their reality. But they are not incased in amber, there for mere contemplation. Like painting and sculpture, and like science and engineering, we can approach music as a fundamentally 'open' entity, saturated with ideas and characterized by a plenitude of responses that constantly change from generation to generation.

Hansen, David T. 2017. Music education as a mirror to humane education. Action, Criticism, and Theory for Music Education 16 (1): 95-100. doi:10.22176/act16.1.95 
What about the dignity of the music teacher? The humanity in Randall's account once again shines forth, because in deeply respecting the dignity of students, and the dignity of music with its many-sided and infinitely rich traditions, he also provides a compelling account of the music educator, at any level of the system. It is a demanding account, as befits the challenge embodied in acknowledging the dignity of others. Through argument and example drawn from many features of life, Randall shows that the conservancy tradition in the field, with its master-apprentice model, has all too often been marked by a lack of recognition of the dignity of the student, of music, and of the teacher. The tradition has marked all three 'players' as discrete, atomistic, self-contained entities lodged in a preset hierarchy. For both student and teacher, this tradition all too often does not heed the life experience that they bring to the encounter with music and which can, in principle, wonderfully 'vitalize' the music itself, in the sense of bringing to life ideas, possibilities, and transformative meanings. The student and teacher must indeed learn and heed technique. But technique must also be, at least in part, in the service of their eros.

Randall demonstrates that to act upon the dignity of student, music, and teacher constitutes a more demanding task than operating in traditional systems of master-apprentice. To act in respect and in response to student, music, and oneself as educator-and all at one and the same time-is a challenging art, especially when we add to it the pressures of conducting music education within institutions that do not always have dignity as their primary concern. But Randall's book convincingly shows what a joyful art this can be. He urges his fellow educators to fuse what I would characterize as a horizontal egalitarianism, in which each voice is heard, with an egalitarianism 'upwards', in which teachers and students constantly encourage one another to take the next step, to face the next difficulty, to sustain their effort, to imagine more intensely and systematically, to meet their eros rather than settle for an easy conformity. Randall's account of the music educator invites a reconstruction, a reimagining, of everything from music teacher preparation, to school and classroom based practices, to modes of assessment, and to modes of communication with various publics regarding what both music and music education are all about. Dignity morphs from an old-fashioned word into a revolutionary call.

Hansen, David T. 2017. Music education as a mirror to humane education. Action, Criticism, and Theory for Music Education 16 (1): 95-100. doi:10.22176/act16.1.95 


\begin{abstract}
About the Author
David T. Hansen is the Weinberg Professor in the Historical and Philosophical Foundations of Education and Director of Program in Philosophy and Education at Teachers College, Columbia University.
\end{abstract}

Hansen, David T. 2017. Music education as a mirror to humane education. Action, Criticism, and Theory for Music Education 16 (1): 95-100. doi:10.22176/act16.1.95 